\title{
Conditioned blood reperfusion markedly enhances neurologic recovery after prolonged cerebral ischemia
}

\author{
Bradley S. Allen, MD \\ Manuel Castellá, MD \\ Gerald D. Buckberg, MD \\ Zhongtou Tan, $\mathrm{PhD}^{\mathrm{b}}$
}

Objectives: To determine whether controlled reperfusion using conditioned leukodepleted blood can substantially limit cerebral reperfusion injury following prolonged ischemia.

Methods: Eighteen pigs $(25-35 \mathrm{~kg})$ underwent 90 minutes of hypothermic circulatory arrest $\left(19^{\circ} \mathrm{C}\right)$ to produce brain ischemia. At the start of rewarming, 10 pigs received uncontrolled reperfusion with unmodified (normal) blood. The other 8 pigs underwent 10 minutes of controlled reperfusion by selectively perfusing both common carotid arteries with blood passed through a CoBRA filter. This filter conditions the blood by removing white blood cells, platelets, and attenuating complement. Two other pigs underwent cooling and rewarming only (controls) without ischemia. Neurologic assessment was done using neurologic deficit scoring $(0=$ normal, $500=$ brain death $)$, and jugular venous samples were obtained for biochemical analysis postreperfusion.

Results: There were no statistical differences in hemodynamics between groups. At 6 hours postanesthesia, all animals receiving normal blood were substantially neurologically impaired. At 24 hours, they all had abnormal positioning and all but 1 were unable to sit or stand (neurologic score $124 \pm 19$ ). In contrast, nonischemic controls and pigs receiving conditioned blood reperfusion showed only minor neurologic deficits at 6 hours, and at 24 hours all were considered normal (neurologic scores 0 and $6 \pm 5 ; P<.005$ vs uncontrolled reperfusion). Compared with pigs receiving normal blood reperfusion, oxygen free radical formation (conjugated dienes $1.70 \pm 0.03$ vs $1.60 \pm 0.02$ Abs $240 \mathrm{~nm} ; P<.05$ vs uncontrolled reperfusion), and endothelin- 1 release $(2.12 \pm 0.09$ vs $1.84 \pm 0.06 \mathrm{pg} / \mathrm{mL} ; P<.05$ vs uncontrolled reperfusion) were also significantly lower in animals receiving conditioned blood.

Conclusions: Following prolonged cerebral ischemia, reperfusion injury is avoided by delivering conditioned blood, which is devoid of white cells, platelets, and membrane attack complex. These results suggest that this modality is clinically useful in situations where the brain is subjected to prolonged ischemia.

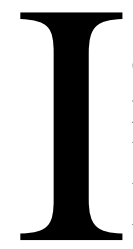
schemia is a passive and time-dependent phenomenon caused by insufficient oxygen and nutrient supply, whereas reperfusion injury is an active process that results in functional, metabolic, and structural alterations with the reintroduction of blood..$^{1-5}$ It is clear that cells appearing undamaged at the end of ischemia may undergo severe injury following reperfusion with unmodified blood. ${ }^{1,2}$ The consequence is that of impaired organ function and increased morbidity and mortality if ischemia is prolonged. Nevertheless, studies in the heart, lung, kidney, and leg show reperfusion damage can be coun- 
teracted by control of the composition of the reperfusate and conditions of reperfusion. ${ }^{1,2,4,6-11}$ Most recently, recovery of cerebral function was demonstrated following deep hypothermic circulatory arrest, where global reperfusion of the entire body by modifying the pump prime reperfusate favorably improved brain function. ${ }^{12}$ Unfortunately, the extent of recovery was not evaluated beyond the acute setting, and specific contributions of different components of the reperfusate solution were not analyzed. Moreover, there was no regional control of cerebral reflow to focus upon selective resuscitation of the brain, the organ most sensitive to ischemia and reperfusion damage.

Reperfusion injury can be mediated by activated constituents of blood, including leukocytes (white blood cells [WBCs]), especially neutrophils, platelets, and complement, specifically the distal components of the complement cascade (C5b-9, membrane attack complex). ${ }^{3,11,13-23}$ Each element can serve as a target of pharmacological or physical interventions designed to reduce reperfusion injury, since attenuation of reperfusion injury was achieved in myocardial and pulmonary tissue by removal of activated WBCs, platelets, or membrane attack complex. However, the importance of these elements in brain reperfusion injury is uncertain.

The present study will determine the degree of involvement of these elements in the reperfusion injury of the brain, using a model of hypothermic circulatory arrest (HCA) to produce cerebral ischemia. This global model was used to produce cerebral ischemia because most nonprimates have extensive neurologic vascular collateral networks, which are not uniformly injured by unilateral or bilateral carotid ligation. ${ }^{12,24}$ Following this ischemic insult, either the brain was reperfused in an uncontrolled manner with normal (unmodified) blood or reperfusion was controlled by selectively perfusing the carotid arteries with blood that was first passed through a Conditioned Blood Reperfusion Application (CoBRA) filter (Pall B-1328 filter, Pall Corporation, East Hills, NY). This filter selectively removes virtually all WBCs and platelets, as well as attenuates various complement proteins including membrane attack complex. ${ }^{12,25}$ The combined effect on WBCs and platelet removal as well as the complement-modulating effect of this filter suggest that this multifactorial approach may provide an optimal way to attenuate reperfusion injury.

Our initial study end point aimed at the potential for functional neurological recovery (using a well-recognized conventional scoring system) after a 24-hour time frame, to allow dissipation of the contributory mental effects of extracorporeal circulation and anesthesia. ${ }^{12,26}$ Our secondary end point of biochemical and hemodynamic recovery was also evaluated but an intact functional neurologic system is the landmark of avoidance of brain injury.

\section{Material and Methods}

Twenty pigs (2-3 months old, $25-35 \mathrm{~kg}$ ) pigs were premedicated with $15 \mathrm{mg} / \mathrm{kg}$ ketamine and $0.5 \mathrm{mg} / \mathrm{kg}$ diazepam intramuscularly. They were then anesthetized with inhaled isoflurane and fentanyl $(5 \mathrm{ug} / \mathrm{kg})$, and the lungs were ventilated using a volume ventilator. All animals received humane care in compliance with the Principles of Laboratory Animal Care published by the National Institutes of Health (publication no. 96-03, revised 1996).

Using sterile techniques, the thoracic artery and vein were cannulated to monitor arterial pressure and for use in blood gas determinations and intravenous infusions. After systemic heparinization $(3 \mathrm{mg} / \mathrm{kg})$ a 10 - to $12-\mathrm{Fr}$ thin-walled cannula was inserted into the femoral artery, a 8- to 20 -Fr short venous cannula placed into the external jugular vein, and a Swan-Ganz catheter placed into the pulmonary artery via the internal jugular vein. Arterial blood gases, electrolytes, and hemoglobin (Blood Gas System 288, Ciba Corning, Midfield, Mass) were measured every 15 to 30 minutes to ensure optimal levels. A heating/cooling blanket was used to maintain the desired core temperature. The cardiopulmonary bypass circuit was heparinized, primed with packed red cells from donor pigs, and made normocalcemic. Hematocrit value was adjusted to $25 \%$ to $35 \%$ with plasmalyte solution. An Affinity NT 541 membrane oxygenator (Medtronic, Inc, Minneapolis, Minn) was used and the systemic flow rate adjusted to approximately 100 to $125 \mathrm{mg} / \mathrm{kg} / \mathrm{min}$ at full flow to maintain continuously monitored aortic root pressures of 50 to 70 $\mathrm{mm} \mathrm{Hg}$. To facilitate venous return, active suction by a centrifugal pump (Biopump BPX-80, Medtronic, Inc) was maintained during bypass.

\section{Experimental Protocol}

All animals were placed on cardiopulmonary bypass using $100 \%$ $\mathrm{FIO}_{2}$, cooled to $19^{\circ} \mathrm{C}$ using an alpha-stat strategy, and placed into 3 experimental groups. In 2 pigs, cardiopulmonary bypass (CPB) was continued without ischemia (controls), and the other 18 underwent 90 minutes of HCA. Following HCA, bypass was restarted at a pressure of 20 to $30 \mathrm{~mm} \mathrm{Hg}$ for 10 minutes (in all pigs) and then slowly increased to 50 to $70 \mathrm{~mm} \mathrm{Hg}$. All pigs were rewarmed to $36^{\circ} \mathrm{C}$ to $37^{\circ} \mathrm{C}$. The heart was defibrillated as needed at $25^{\circ} \mathrm{C}$ and all pigs were started on $10 \mu \mathrm{g} \cdot \mathrm{kg}^{-1} \cdot \mathrm{min}^{-1}$ of dopamine when core temperature reached $35^{\circ} \mathrm{C}$. Dopamine was then either increased or weaned to keep systolic arterial pressure above $70 \mathrm{~mm} \mathrm{Hg}$ and was discontinued only when arterial pressure was maintained greater than $70 \mathrm{~mm} \mathrm{Hg}$ for 5 minutes. Hemodynamic measurements were obtained before (baseline) and $30 \mathrm{~min}$ utes post-CPB. Biochemical measurements were made from samples taken from the internal jugular vein 5 minutes after initiating CPB (baseline), immediately prior to hypothermic $\left(19^{\circ} \mathrm{C}\right)$ circulatory arrest, during rewarming when the temperature reached $36^{\circ} \mathrm{C}$ to $37^{\circ} \mathrm{C}$, and at 4 and 24 hours post-CPB. Following the hemodynamic measurements, protamine was given and all cannulas removed. Bleeding was controlled, the vessels repaired, and all wounds closed. The animals were then allowed to regain consciousness and were extubated; they underwent neurologic assessment approximately 6 and 24 hours later. Fentanyl $(0.2-0.3 \mathrm{ug} / \mathrm{kg})$ was given as needed for postoperative pain but was held for at least 
2 hours prior to the neurologic evaluation. The animals were then killed.

\section{Experimental Groups}

Controls To distinguish the effects of extracorporeal circulation alone without ischemia, 2 pigs underwent cooling to $19^{\circ} \mathrm{C}$ and immediate rewarming to $37^{\circ} \mathrm{C}$.

Hypothermic circulatory arrest After cooling to $19^{\circ} \mathrm{C}$, the other 18 pigs underwent 90 minutes of hypothermic circulatory arrest and were reperfused using either the unmodified (normal) blood prime (uncontrolled reperfusion) or selective carotid reperfusion (controlled reperfusion) with conditioned blood.

Unmodified blood (uncontrolled) reperfusion Following $\mathrm{HCA}, \mathrm{CPB}$ was reinstituted in 10 pigs (pressure $20-30 \mathrm{~mm} \mathrm{Hg}$ ) without altering the pump blood bypass prime. This simulates the conventional clinical method to reperfuse the brain following ischemia.

Conditioned blood (controlled) reperfusion In 8 pigs, the common carotid arteries were exposed during circulatory arrest. Each received a carotid artery graft, harvested from blood donor pigs, into each carotid artery. A "Y"-shaped cannula was inserted into the tip of each graft to selectively reperfuse both vessels at the initiation of $\mathrm{CPB}$, which started at the beginning of rewarming (initiation of $\mathrm{CPB}$ ). Each pig underwent 10 minutes of selective (regional) common carotid perfusion with white cell and plateletfree, complement attenuated blood by passing the blood prime through 6 parallel CoBRA filters (Pall B-1328 filter, Pall Corporation). A pressure-tip needle was inserted into the carotid graft to monitor perfusion pressure, which was kept at $30 \pm 4 \mathrm{~mm} \mathrm{Hg}$, ensuring at least $200 \mathrm{~mL} / \mathrm{min}$ reflow. During regional carotid perfusion, systemic blood (CPB) pressure was maintained at 20 $\mathrm{mm} \mathrm{Hg}$ to minimize unfiltered collateral brain blood flow via vertebral vessels. At the end of controlled reperfusion, the grafts were closed by clipping them above the anastomosis to restore carotid flow through the pig's native carotid vessel.

\section{Physiologic and Biochemical Determinations}

Hemodynamic measurements Hemodynamic measurements were made before and 30 minutes after discontinuing CPB. Cardiac output was determined by duplicate injections of $4^{\circ} \mathrm{C}$ cold saline solution into the Swan-Ganz catheter. Cardiac output and pulmonary vascular resistance were calculated as previously described. ${ }^{7,27}$ Dopamine requirements are expressed as the total time each animal received inotropic support.

Conjugated dienes Conjugated dienes, a marker of oxidantmediated lipid peroxidation, were determined as previously described and expressed as the absorbency (A) at a wave length of $240 \mathrm{~nm} / 0.5$ mL plasma. $^{12,27}$

Creatinine kinase and serum transaminase Cellular injury was determined by measuring creatinine kinase (CK) and serum transaminase (AST) activity by the ultraviolet spectrophotometric method (Sigma Chemical Co, St Louis, Mo) and expressed as $\mathrm{U} / \mathrm{mL}$ plasma.

Endothelin-1 Vascular injury was determined by measuring endothelin levels by an Enzyme Immunometric Assay (ACE EIA Kit, Cayman Chemical Co, Ann Arbor, Mich) and expressed as $\mathrm{pg} / \mathrm{mL}$ plasma.
TABLE 1. Neurologic deficit scoring

\begin{tabular}{|c|c|c|c|c|}
\hline & Side* & Normal & Weak & Absent \\
\hline \multicolumn{5}{|l|}{ Central nerve function } \\
\hline Pupil size & $R, L$ & 0 & 2 & 5 \\
\hline Light reflex & $\mathrm{R}, \mathrm{L}$ & 0 & 2 & 5 \\
\hline Eye position & $\mathrm{R}, \mathrm{L}$ & 0 & 2 & 5 \\
\hline Lid reflex & $\mathrm{R}, \mathrm{L}$ & 0 & 2 & 5 \\
\hline Corneal reflex & $\mathrm{R}, \mathrm{L}$ & 0 & 2 & 5 \\
\hline Ciliospinal reflex & $\mathrm{R}, \mathrm{L}$ & 0 & 2 & 5 \\
\hline Occulocephalic reflex & & 0 & 5 & 10 \\
\hline Auditory reflex & & 0 & 5 & 10 \\
\hline Gag reflex & & 0 & 5 & 10 \\
\hline Carinal reflex & & 0 & 5 & 10 \\
\hline \multicolumn{5}{|l|}{ Respiration } \\
\hline Normal & & & & 0 \\
\hline Hyperventilation & & & & 25 \\
\hline Abnormal & & & & 50 \\
\hline Apnea & & & & 100 \\
\hline \multicolumn{5}{|l|}{ Motor and sensory function } \\
\hline Stretch reflex & & 0 & 10 & 25 \\
\hline Motor response to pain & & 0 & 10 & 25 \\
\hline Positioning & & 0 & 10 & 25 \\
\hline Muscle tonus & & 0 & 10 & 25 \\
\hline \multicolumn{5}{|l|}{ Level of consciousness } \\
\hline Normal & & & & 0 \\
\hline Cloudy & & & & 30 \\
\hline Delirium & & & & 45 \\
\hline Stupor & & & & 60 \\
\hline Coma & & & & 100 \\
\hline \multicolumn{5}{|l|}{ Behavior } \\
\hline Drinking & & 0 & - & 15 \\
\hline Chewing & & 0 & - & 15 \\
\hline Sitting & & 0 & - & 15 \\
\hline Standing & & 0 & - & 15 \\
\hline Walking & & 0 & 20 & 40 \\
\hline
\end{tabular}

$R$, Right; $L$, left. Total $=$ sum of all sections $(0=$ normal, $500=$ brain death). ${ }^{*}$ Score each side separately.

Neurologic injury Neurologic assessment was performed in all animals 6 hours after wounds were closed and after the animal was extubated (approximately 7 hours post-CPB). The last 5 animals in each group also underwent detailed neurologic evaluation at 24 hours. An adaption of neurologic deficit scoring described elsewhere was used, and a summary of the variables assessed are listed in Table 1. ${ }^{12,26}$ In neurologic deficit scoring, 5 general components of the neurologic examination are evaluated and a score of 100 is assigned to each category. A total score of 500 indicates brain death and a score of 0 is normal. Neurologic deficit scoring was always agreed upon by 2 members of the laboratory team.

\section{Statistics}

All data are expressed as mean \pm SE. Statistical analysis of data within and between groups was performed using multiple analysis of variance followed by application of the Student $t$ test with Tukey-Kramer correction for multiplicity. Data at 24 hours was analyzed using nonparametric Wilcoxon test. Changes within and between groups were considered statistically significant when the $P$ value was less than .05 . 
TABLE 2. Hemodynamic data

\begin{tabular}{|c|c|c|c|c|c|c|c|c|c|}
\hline & $\begin{array}{c}\text { MAP } \\
(\mathrm{mm} \mathrm{Hg})\end{array}$ & $\begin{array}{l}\text { Heart } \\
\text { rate }\end{array}$ & $\begin{array}{c}\text { MPAP } \\
(\mathrm{mm} \mathrm{Hg})\end{array}$ & $\begin{array}{c}\text { LAP } \\
(\mathrm{mm} \mathrm{Hg})\end{array}$ & $\begin{array}{c}\text { Cardiac } \\
\text { output } \\
\text { (L/min) }\end{array}$ & LVSWI & SVR & PVR & $\begin{array}{c}\text { Dopamine } \\
\text { (min) }\end{array}$ \\
\hline \multicolumn{10}{|l|}{ Baseline } \\
\hline No HCA (controls) & 67 & 107 & 15 & 9 & 3.9 & 28 & 1200 & 143 & \\
\hline Normal reperfusion & $66 \pm 4$ & $94 \pm 4$ & $13 \pm 1$ & $6 \pm 1$ & $4.2 \pm 0.6$ & $33 \pm 6$ & $1327 \pm 174$ & $153 \pm 28$ & \\
\hline Conditioned reperfusion & $57 \pm 3$ & $93 \pm 3$ & $12 \pm 1$ & $6 \pm 1$ & $3.7 \pm 0.5$ & $30 \pm 5$ & $1214 \pm 130$ & $149 \pm 34$ & \\
\hline After CPB & & & & & & & & & \\
\hline No HCA (controls) & 53 & 150 & 18 & 7 & 3.2 & 12 & 1015 & 130 & 0 \\
\hline Normal reperfusion & $68 \pm 7$ & $144 \pm 15$ & $20 \pm 2$ & $5 \pm 1$ & $4.2 \pm 0.5$ & $25 \pm 4$ & $1195 \pm 176$ & $343 \pm 73$ & $134 \pm 22$ \\
\hline Conditioned reperfusion & $62 \pm 5$ & $134 \pm 11$ & $25 \pm 3$ & $7 \pm 1$ & $3.8 \pm 0.6$ & $26 \pm 4$ & $1318 \pm 202$ & $492 \pm 123$ & $145 \pm 20$ \\
\hline
\end{tabular}

$M A P$, Mean arterial pressure; MPAP, mean pulmonary artery pressure; $L A P$, left atrial pressure; $L V S W I$, left ventricular stroke work index; $S V R$, systemic vascular resistance; PVR, pulmonary vascular resistance; $H C A$, hypothermic circulatory arrest; $C P B$, cardiopulmonary bypass.

TABLE 3. Neurologic evaluation 24 hours postanesthesia

\begin{tabular}{lcc}
\hline & $\begin{array}{c}\text { Normal blood } \\
\text { reperfusion }\end{array}$ & $\begin{array}{c}\text { Conditioned blood } \\
\text { reperfusion }\end{array}$ \\
\hline $\begin{array}{l}\text { Level of consciousness } \\
\text { Normal } \\
\text { Cloudy }\end{array}$ & $2(40 \%)$ & $5(100 \%)$ \\
Motor/sensory function & $3(60 \%)$ & 0 \\
$\quad \begin{array}{l}\text { Abnormal positioning } \\
\text { Behavior }\end{array}$ & $5(100 \%)$ & 0 \\
Drinking & & \\
Chewing & 0 & $5(100 \%)$ \\
Sitting & $5(100 \%)$ & $5(100 \%)$ \\
Standing & $2(40 \%)$ & $5(100 \%)$ \\
Walking & $1(20 \%)$ & $5(100 \%)$ \\
\hline
\end{tabular}

Data expressed as absolute number and percentage of animals of each group.

\section{Results}

Results are shown in Tables 2 and 3 and Figures 1 and 2. There were no statistical differences $(P>.2)$ between normal and conditioned blood reperfusion groups for cooling (41 \pm 8 and $38 \pm 10$ minutes) or rewarming time $(82 \pm$ 17 and $87 \pm 19$ minutes).

\section{Hemodynamic and Pulmonary}

All pigs remained in stable condition through out the experimental procedure. Hemodynamic parameters were similar in both groups before and after CPB (Table 2). Dopamine was consistently required (range 58-240 minutes post-CPB) with no differences $(P>.2)$ between ischemic groups. Oxygen administration was required in most animals for 2 hours after extubation, with no differences between groups.

\section{Biochemical}

No difference between groups $(P>.2)$ was noted for control (baseline) values of conjugated dienes $(0.90 \pm 0.03$ Abs $240 \mathrm{~nm})$, endothelin-1 (0.94 $\pm 0.04 \mathrm{pg} / \mathrm{mL})$, creatinine kinase $(383 \pm 23 \mathrm{u} / \mathrm{L})$, or AST $(30 \pm 3 \mathrm{u} / \mathrm{L})$. None of the parameters measured were modified by cooling to $19^{\circ} \mathrm{C}$. Conjugated dienes and endothelin-1 levels remained within baseline levels in pigs not undergoing ischemia (controls), whereas a twofold rise was observed in animals undergoing circulatory arrest. However, both conjugated dienes and endothelin levels were appreciably higher in pigs receiving unmodified blood reperfusion (Figure 1, $A$ and $B$ ). Parameters of cellular injury also rose after ischemia. CK levels rose in all groups, probably as a result of limb ischemia from femoral cannulation (Figure 1,C). It was further increased in animals undergoing circulatory arrest. Nevertheless, CK was lower in pigs receiving conditioned blood compared with those receiving unmodified blood. Postreperfusion, the AST levels rose to $265 \pm 12 \mathrm{U} / \mathrm{mL}$ and 259 $\pm 11 \mathrm{U} / \mathrm{mL}$ in animals receiving unmodified and conditioned blood, respectively, compared with $123 \mathrm{U} / \mathrm{mL}$ in the control group, with no statistical differences $(P>.2)$ between ischemic (HCA) groups. These levels declined to 181 \pm 6 and $167 \pm 6$ by 24 hours.

\section{Neurologic Function}

Postbypass neurologic function is depicted in Table 3 and Figure 2. Extubation time after weaning from anesthesia was similar in all groups. Pigs undergoing cooling and immediate rewarming with no ischemia (controls) developed no significant neurologic deficits at 6 hours postanesthesia. In them, neurological recovery was almost normal, with only unbalanced walking noted, and by 24 hours it was considered normal (neurologic score 0).

In contrast, animals subjected to 90 minutes of hypothermic arrest followed by reperfusion with normal blood (uncontrolled reperfusion) presented with major neurological deficits at 6 hours, and these defects were still present at 24 hours (neurologic score $124 \pm 19$ ). No pig was able to walk or drink, and only 1 pig was able to stand.

These adverse effects of uncontrolled reperfusion were completely reversed by use of a conditioned reperfusate. Pigs receiving controlled reperfusion of the carotid arteries 

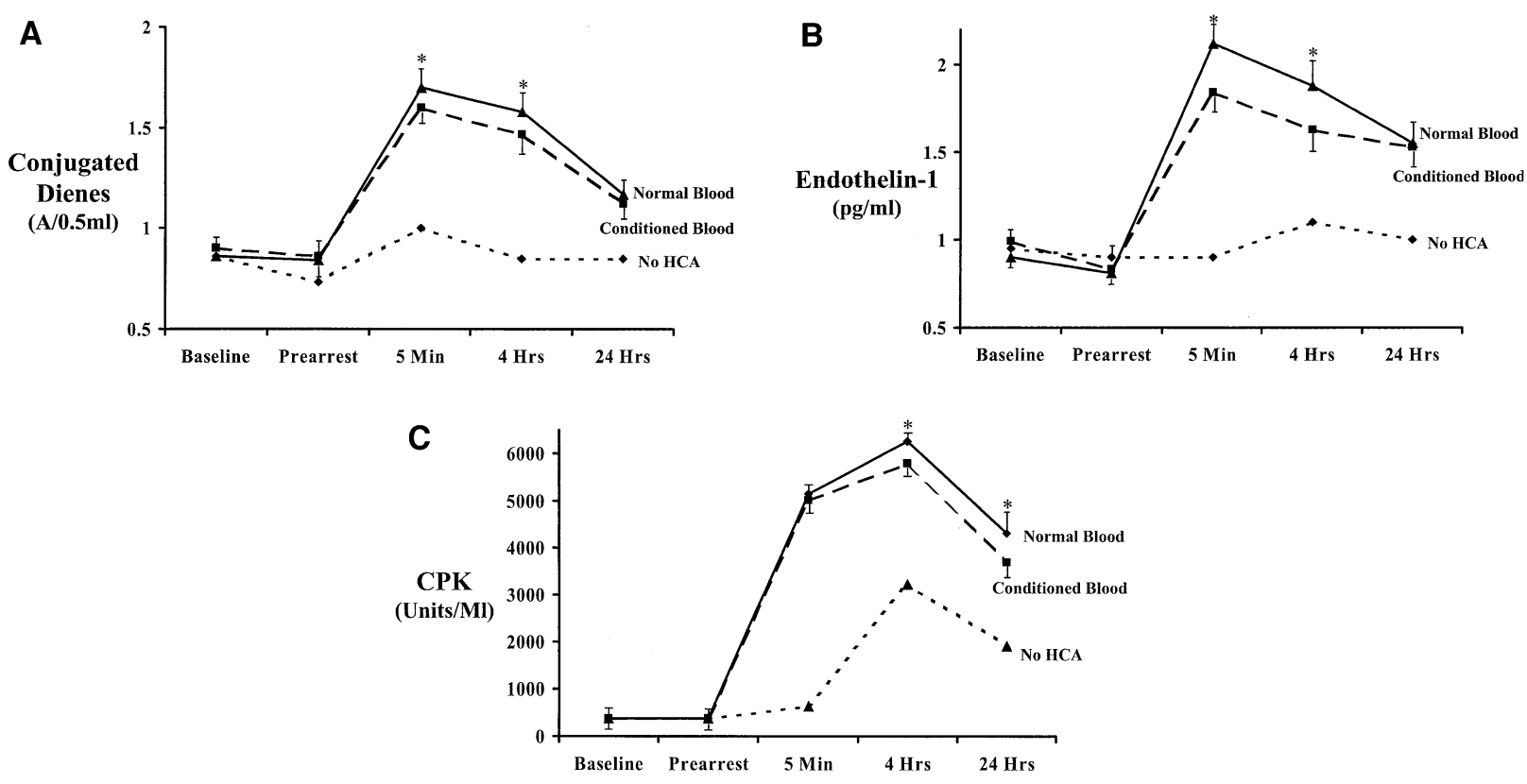

Figure 1. Oxidant-mediated lipid peroxidation measured as conjugated dienes (A), endothelin-1 (B), and creatinine kinase (C) plasma levels in internal jugular vein at different stages of the experiment, depending on the type of carotid reperfusion. ${ }^{*} P<.05$ between ischemic groups. HCA, Hypothermic circulatory arrest.

with conditioned blood presented recovery of neurologic findings that were similar to pigs undergoing no brain ischemia (controls). They presented only mild neurologic impairment at 6 hours and the examination was essentially normal at 24 hours, with each pig able to walk and feed himself (neurologic score $6 \pm 5$ ).

\section{Discussion}

This study shows that reperfusion injury is a major factor of neurologic damage after an ischemic insult and that it can be reduced by controlling the initial period of reperfusion with conditioned blood devoid of leukocytes, platelets, and complement (membrane attack complex). The improved, nearnormal neurologic function was also associated with reduced formation of oxygen free radicals and vascular injury. These findings imply that WBCs, platelets, and complement play an important role in triggering neurologic damage because pigs receiving normal blood reperfusion demonstrated major neurologic deficits. Although we did not extend this observation time beyond 24 hours, previous data using similar circulatory arrest times and longer follow-up did not demonstrate reversibility of this brain injury. ${ }^{26,28,29}$

There is, of course, a limitation of our observations in this pilot study as we did not examine the brain histologically or evaluate specific biochemical markers of injury (ie, S-100 protein, neuron-specific enolase). Neurologic deficit scoring, however, directly correlates with pathologic examination and the release of biochemical markers of injury and more importantly is the hallmark of brain recovery. ${ }^{26,28-30}$

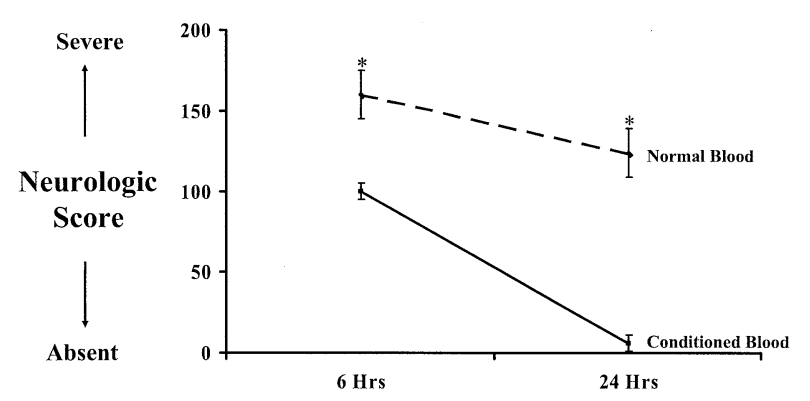

Figure 2. Neurologic injury 6 and 24 hours after discontinuing cardiopulmonary bypass assessed by neurologic deficit scoring. A score of $\mathbf{0}$ equals normal and $\mathbf{5 0 0}$ equals brain dead. Scoring system is shown in Table $1 .{ }^{*} P=.02$ at 6 hours and $P<.005$ at 24 hours.

Our findings show that pigs who received conditioned blood were neurologically completely normal, implying no major pathologic damage.

Moreover, a significant reduction in neurologic damage after circulatory arrest has been demonstrated after WBC filtration alone in chronic animals observed for several days. ${ }^{28}$ However, these investigators used a relatively inefficient WBC filter. In contrast, we suspect that using a CoBRA filter, which is not only more effective in removing WBCs but also removes platelets and attenuates complement, should vastly improve the results, as others have shown that more effective WBC filters dramatically reduce damage. , $^{4,7,10,12,17,25,31}$ 
WBCs are involved mainly in the maintenance of the immune system but under the altered conditions of normal blood reperfusion after ischemia may cause damage to myocardial, pulmonary, or vascular tissue. ${ }^{4,7,17,31}$ Leukocyte depletion is a readily available method that allows the surgeon to safely minimize the harmful effects of neutrophils without risking side effects of pharmacologic interventions aimed at altering leukocyte function or preventing the free radical injury through the use of exogenous oxygen radical scavengers. WBCs have a variety of deleterious effects. ${ }^{4,7,12,17,25,31,32}$ Under conditions of hypoxemia or ischemia, vascular endothelium expresses sites that bind neutrophils on reperfusion. Once bound, the neutrophil may be activated by several different mechanisms. The bound activated neutrophil is then involved in pathways that contribute to cellular injury, as well as releasing substances that are chemotactic for other neutrophils and macrophages, resulting in an amplification of the inflammatory response.

Although WBCs can injure tissue by several mechanisms, numerous studies have demonstrated the production of oxygen radicals is probably the major factor responsible for cellular damage. ${ }^{4,7,10,17,31,32}$ This explains the reduction in oxygen free radical formation (lower conjugated dienes) in pigs receiving leukodepletion, as well as the reduction in vascular damage (decreased endothelin-1) because activated WBCs cannot cause damage to the vascular endothelium if they are removed.

Platelets may act synergistically with WBCs to promote reperfusion injury. ${ }^{12,17,21,23,25,33}$ Activated platelets and WBCs form aggregates that may restrict blood flow in vascular beds. In addition, platelet factor 3 as well as platelet-derived microparticles stimulate neutrophils. Platelets can also release harmful substances such as thromboxane, which can lead to vasoconstriction and other damaging effects that can further promote cellular damage. These considerations make platelet reduction a desirable property of blood conditioning.

The third component in conditioned blood is complement. Plasma is operative in development of reperfusion injury and can augment the leukocyte-mediated components of reperfusion injury. ${ }^{18-20,22,25}$ Complement activation occurs during routine CPB and further activates WBCs and platelets, increasing cellular injury in the setting of reperfusion. Several components of the complement cascade are anaphalotoxins but the distal component (C5a-9, membrane attack complex) is the most damaging, as it can injure cellular membranes directly and increases cell membrane permeability. ${ }^{18-20}$ Moreover, membrane attack complex has an important function in mediating the recruitment of neutrophils to the reperfused cell through local induction of interleukin-8 (IL-8). Membrane attack complex deposition may increase the concentration of the endothelial cell-de- rived neutrophil chemotactant, IL-8, and blocking this may attenuate WBC extravasation into the interstitial space.

Conditioned blood reperfusion of the carotid arteries was accomplished using a CoBRA filter. This filter reduces leukocytes and platelets by $99.99 \%$ and attenuates or removes complement proteins, especially membrane attack complex. ${ }^{12,25}$ The combined WBC/platelet reduction and complement attenuating blood conditioning effect provides an ideal technological approach to positively impact on reperfusion injury. However, the CoBRA filter can only accommodate flows up to 100 to $150 \mathrm{cc} / \mathrm{min}$ and becomes fully saturated after 500 to $750 \mathrm{cc}$ of blood. Therefore, we pumped the blood through 6 filters in a parallel system before being administered to both common carotid arteries through a "Y" cannula and arterial grafts. This system allows up to $600 \mathrm{~mL} / \mathrm{min}$ flow with a maximum filtration capacity of $3 \mathrm{~L}$.

Only the blood components of the reperfusate process were altered in this study but the benefits of controlled reperfusion are consistent with our prior studies, where the reperfusion damage caused by restoring normal blood supply to the kidney, heart, lung, extremity, and whole body was offset by controlling both blood components and other metabolic and mechanical factors during the initial period of reperfusion. ${ }^{1,2,4,6-12}$ Nevertheless, controlled reperfusion is not just removing the various blood components but changing the composition of the reperfusate and the conditions of reperfusion. ${ }^{1,2,4}$ Modifying constituents such as oxygen, glucose, osmolarity, $\mathrm{pH}$, calcium, and magnesium would probably also enhance neurologic recovery but was not tested in these studies so that we could define the effect of the blood components without other confounding variables.

A lower initial reperfusion pressure $(20-30 \mathrm{~mm} \mathrm{Hg}$ ) reduces cellular damage in the heart, lung, and brain. ${ }^{2,4,11,34}$ This lower pressure was used in both groups of pigs undergoing ischemia, both to keep blood filtration as the only variable and to reduce collateral flow via vertebral vessels. We did not study a higher perfusion pressure, which is conventionally used when an occluded artery is acutely reopened, so that the effects of limiting this variable were not tested. Nevertheless, we strongly believe, based on our prior experience, that modifying the composition of the reperfusate as well as the conditions of reperfusion (ie, pressure) are vital adjuncts in limiting reperfusion damage and should always be use in concert with CoBRA filtration.

A model of 90 minutes of circulatory arrest was used to produce brain ischemia, as most nonprimates have extensive neurologic vascular collaterals. ${ }^{24}$ Ligating 1 or both carotid arteries often results in no significant brain ischemia so that the initiating insult is not consistent. Therefore, circulatory arrest became a reliable way to produce a consistent and uniform cerebral insult in the pig. This model has also been used by other investigators and results in a rela- 
tively homogeneous neurologic insult. ${ }^{26,28,29,35}$ We suspect this insult mimics acute regional cerebral ischemia (ie, arterial occlusion) in primates, and we hope the findings can be applicable to any form of brain ischemia. The complete neurologic recovery is a new and previously unreported finding and sets the stage for further studies of longer intervals of brain ischemia, where this aspect of controlled reperfusion can both be extended and, more importantly, possible integration with other methods of reducing reperfusion damage.

Plasma levels of conjugated dienes and endothelin-1 were significantly lower in the conditioned blood group, suggesting that oxygen radical injury and vascular injury were better controlled. Nevertheless, the biochemical results may have been misleading and almost certainly underestimated the improvement with CoBRA filtration. Blood was taken from the jugular vein only after rewarming to $37^{\circ} \mathrm{C}$. By this time, a generalized reperfusion injury would have taken place in every organ, releasing oxygen free radicals (conjugated dienes), endothelin (vascular damage), $\mathrm{CK}$, and AST into the systemic pump blood. Therefore, the samples from both ischemic groups presented higher levels than control nonischemic animals, as elevations in jugular venous samples reflected the higher circulating levels produced by other organs. Systemic perfusion was initiated at the same time as selective carotid perfusion, and so it is possible that some unmodified (unfiltered) blood perfused portions of the brain, increasing the neurologic injury. Jugular venous samples may also be contaminated by drainage from nonneurologic tissue. Sampling immediately after reperfusion or obtaining simultaneous cerebral arterial and venous samples would have been a better way of specifically quantifying brain production but this was not done. Nevertheless, the data support a reduction in brain injury, as any differences in biochemical levels must reflect a limitation of cerebral injury because conditioned blood was only delivered to the brain.

In conclusion, this study confirms that reperfusion injury is a major cause of neurological cell damage after an ischemic insult and demonstrates that reperfusion injury can be significantly limited by controlling the initial period of reperfusion using conditioned blood devoid of WBCs, platelets, and complement. Incorporating this modality during direct cerebral reperfusion may allow surgeons to reduce the damage following cerebral ischemia, potentially leading to a significant reduction in morbidity and mortality and improved patient outcome.

The authors wish to thank Ms Christina Green for her organizational and secretarial assistance.

\section{References}

1. Allen BS, Okamoto F, Buckberg GD, et al. Studies of controlled reperfusion after ischemia $\mathrm{XV}$ : immediate functional recovery after 6 hours of regional ischemia by careful control of conditions of reper- fusion and composition of reperfusate. $J$ Thorac Cardiovasc Surg. 1986;92:S621-35.

2. Buckberg GD, Allen BS. Myocardial protection management during adult cardiac operations. In: Baue AE, Geha AS, Hammond GL, Laks H, Naunheim KS, editors. Glenn's thoracic and cardiovascular surgery. 6th ed. Stamford, CT: Appleton \& Lange; 1995. p. 165387.

3. Boyle JR, Pohlman TH, Cornejo CJ, Verrier ED. Ischemia-reperfusion injury. Ann Thorac Surg. 1997;64:S24-30.

4. Allen BS, Barth MJ, Ilbawi M. Pediatric myocardial protection: an overview. Semin Thorac Cardiovasc Surg. 2001;13:56-72.

5. Piper HM, Garcia-Dorado D, Ovize M. A fresh look at reperfusion injury. Cardiovasc Res. 1998;38:291-300.

6. Beyersdorf F, Mitrev Z, Ihnken K, et al. Controlled limb reperfusion in patients having cardiac operations. J Thorac Cardiovasc Surg. 1996;111:873-81.

7. Halldorsson A, Kronon M, Allen BS, et al. Controlled reperfusion after lung ischemia: implications for improved function after lung transplantation. J Thorac Cardiovasc Surg. 1998;115:415-25.

8. Kronon MT, Allen BS, Rahman SK, et al. Reducing postischemic reperfusion damage in neonates using a terminal warm substrate enriched blood cardioplegic reperfusate. Ann Thorac Surg. 2000;70:76570.

9. Julia P, Haab F, Sabatier B, et al. Improvement of postischemic kidney function by reperfusion with a specifically developed solution (BT01). Ann Vasc Surg. 1995;9(Suppl):81-8.

10. Halldorsson A, Kronon M, Allen BS, et al. Controlled reperfusion prevents pulmonary injury after 24-hours of lung preservation. Ann Thorac Surg. 1998;66:877-85.

11. Allen BS. The role of leukodepletion in myocardial, pulmonary and lower extremity ischemia. Perfusion. 2002;17:11-22.

12. Allen BS, Buckberg GD, Aeberhard E, Ignarro LJ. Deep hypothermic circulatory arrest and global reperfusion injury: avoidance by making a pump prime reperfusate; a new concept. J Thorac Cardiovasc Surg. 2003;125:628-32.

13. Byrne J, Appleyard R, Lee C, et al. Controlled reperfusion of the regionally ischemic myocardium with leukocyte-depleted blood reduces stunning, the no-reflow phenomenon, and infarct size. J Thorac Cardiovasc Surg. 1992;103:66-72.

14. Gu YJ, de Vries AJ, Boonstra PW, van Oeveren W. Leukocyte depletion results in improved lung function and reduced inflammatory response after cardiac surgery. J Thorac Cardiovasc Surg. 1996;112: 494-500.

15. Morioka K, Muraoka R, Chiba Y, et al. Leukocyte and platelet depletion with a blood cell separator: effects on lung injury after cardiac surgery with cardiopulmonary bypass. $J$ Thorac Cardiovasc Surg. 1996;111:45-54.

16. Chiba Y, Morioka K, Muraoka R, et al. Effects of depletion of leukocytes and platelets on cardiac dysfunction after cardiopulmonary bypass. Ann Thorac Surg. 1998;65:107-13.

17. Kronon MT, Allen BS, Halldorsson A, Rahman SK, Wang T, Ilbawi M. L-arginine, prostaglandin, and white cell filtration equally improve myocardial protection in stressed neonatal hearts. J Thorac Cardiovasc Surg. 1999;118:665-73.

18. Vakeva AP, Agah A, Rollins SA, Matis LA, Li L, Stahl GL. Myocardial infarction and apoptosis after myocardial ischemia and reperfusion: role of the terminal complement components and inhibition by anti-C5 therapy. Circulation. 1998;97:2259-67.

19. Gardinali M, Conciato L, Cafaro C, Agostoni A. Complement system in coronary heart disease: a review. Immunopharmacology. 1995;30: 105-17.

20. Rinder CS, Rinder HM, Smith BRE. Blockade of C5a and C5b-9 generation inhibits leukocyte and platelet activation during extracorporeal circulation. J Clin Invest. 1995;96:1564-72.

21. Lefer AM, Campbell B, Scalia R, Lefer DJ. Synergism between platelets and neutrophils in provoking cardiac dysfunction after ischemia and reperfusion: role of selections. Circulation. 1998;98: 1322-8.

22. Buerke M, Prufer D, Dahm M, Oelert H, Merer J, Darius H. Blocking of classical complement pathway inhibits endothelial adhesion mole- 
cule expression and preserves ischemic myocardium from reperfusion injury. J Pharmacol Exp Ther. 1998;286:429-38.

23. Ko W, Lang D, Hawes AS, Zelano JA, Isom OW, Krieger KH Platelet-activating factor antagonism attenuates platelet and neutrophil activation and reduces myocardial injury during coronary reperfusion. J Surg Res. 1993;55:504-15.

24. Haaland K, Orderud WJ, Thoresen M. The piglet as a model for cerebral circulation: an angiographic study. Biol Neonate. 1995;68:7580.

25. Patel MB, Kilgore KS, Ortolano GA, et al. Conditioned blood reperfusion during angioplasty (CoBRA) treatment of acute myocardial infarction. Perfusion. 2001;16(Suppl):39-49.

26. Forbess JM, Ibla JC, Lidov HGW, et al. University of Wisconsin cerebroplegia in a piglet survival model of circulatory arrest. Ann Thorac Surg. 1995;60(6 Suppl):S494-S500.

27. Ihnken K, Morita K, Buckberg GD, Sherman MP, Young HH. Studies of hypoxemic/reoxygenation injury: without aortic clamping. III. Comparison of the magnitude of damage by hypoxemia/reoxygenation versus ischemia/reperfusion. J Thorac Cardiovasc Surg. 1995;110: 1182-9.

28. Priestley MA, Golden JA, O'Hara IB, McCann J, Kurth CD. Comparison of neurologic outcome after deep hypothermic circulatory arrest with alpha-stat cardiopulmonary bypass in newborn pigs. $J$ Thorac Cardiovasc Surg. 2001;336-43.

29. Rimpilainen J, Pokela M, Kiviluoma K, et al. Leukocyte filtration improves brain protection after a prolonged period of hypothermic circulatory arrest: a study in a chronic porcine model. $J$ Thorac Cardiovasc Surg. 2000;120:1131-41.

30. Bellinger DC, Wypij D, du Plessis AJ, et al. Developmental and neurologic effects of alpha-stat versus ph-stat strategies for deep hypothermic cardiopulmonary bypass in infants. $J$ Thorac Cardiovasc Surg. 2001;121:374-83.

31. Allen BS, Ilbawi MN. Hypoxia, reoxygenation and the role of systemic leukodepletion in pediatric heart surgery. Perfusion. 2001; 16(Suppl):19-29.

32. Allen BS, Rahman SK, Ilbawi M, Feinberg H, Bolling KS, Kronon M. The detrimental effects of cardiopulmonary bypass in cyanotic infants: preventing the reoxygenation injury. Ann Thorac Surg. 1997;64:1381-8.

33. Rinder CS, Gaal D, Student LA, Smith BR. Platelet-leukocyte activation and modulation of adhesion receptors in pediatric patients with congenial heart disease undergoing cardiopulmonary bypass. J Thorac Cardiovasc Surg. 1994;107:280-8.

34. Castaneda AR, Jonas RA, Mayer JE Jr, Hanley FL. Cardiopulmonary bypass, hypothermia, and circulatory arrest. In: Castaneda AR, Jonas RA, Mayer JE Jr, Hanley FL, editors. Cardiac surgery of the neonate and infant. Philadelphia: WB Saunders; 1994. p. 23-39.

35. Nollert G, Nagashima M, Bucerius J, et al. Oxygenation strategy and neurologic damage after deep hypothermic circulatory arrest. II. Hypoxic versus free radical injury. J Thorac Cardiovasc Surg. 1999;117: 1172-9. 